\title{
Differences in Cardiovascular Disease Risk Factor Management in Primary Care by Sex of Physician and Patient
}

\author{
Hava Tabenkin, MD, MS, LLB ${ }^{1,2}$ \\ Charles B. Eaton, $M D, M S^{3,4,5}$ \\ Mary B. Roberts, MS \\ Donna R. Parker, ScD $D^{3,4}$ \\ Jerome H. McMurray, MA $^{3}$ \\ Jeffrey Borkan, $M D, P b D^{3,5}$ \\ 'Department of Family Medicine, \\ HaEmek Medical Center, Afula, Israel
}

${ }^{2}$ The Division of Health in the Community, Ben Gurion University of the Negev, Beer Sheva, Israel

${ }^{3}$ Center for Primary Care and Prevention, Memorial Hospital of Rhode Island, Pawtucket, Rhode Island

${ }^{4}$ Department of Community Health, Warren Alpert Medical School of Brown University, Providence, Rhode Island

${ }^{5}$ Department of Family Medicine, Warren Alpert Medical School of Brown University, Providence, Rhode Island

Conflicts of interest: none reported

\section{CORRESPONDING AUTHOR}

Charles B. Eaton, MD, MS

Center for Primary Care and Prevention

Memorial Hospital of Rhode Island

111 Brewster St

Pawtucket, RI 02860

Charles_Eaton@mhri.org

\begin{abstract}
PURPOSE The purpose of this study was to evaluate differences in the management of cardiovascular disease (CVD) risk factors based upon the sex of the patient and physician and their interaction in primary care practice.
\end{abstract}

METHODS We evaluated CVD risk factor management in 4,195 patients cared for by 39 male and 16 female primary care physicians in 30 practices in southeastern New England.

RESULTS Many of the sex-based differences in CVD risk factor management on crude analysis are lost once adjusted for confounding factors found at the level of the patient, physician, and practice. In multilevel adjusted analyses, styles of CVD risk factor management differed by the sex of the physician, with more female physicians documenting diet and weight loss counseling for hypertension (odds ratio $[\mathrm{OR}]=2.22 ; 95 \%$ confidence interval $[\mathrm{Cl}], 1.12-4.40$ ) and obesity $(\mathrm{OR}=2.14 ; 95 \% \mathrm{Cl}, 1.30-3.51)$ and more physical activity counseling for obesity $(\mathrm{OR}=2.03 ; 95 \% \mathrm{Cl}, 1.30-3.18)$ and diabetes $(\mathrm{OR}=6.55 ; 95 \% \mathrm{Cl}, 2.01-21.33)$. Diabetes management differed by the sex of the patient, with fewer women receiving glucose-lowering medications ( $\mathrm{OR}=0.49 ; 95 \% \mathrm{Cl}, 0.25-0.94)$, angiotensin-converting enzyme inhibitor therapy $(\mathrm{OR}=0.39 ; 95 \% \mathrm{Cl}, 0.22-0.72)$, and aspirin prophylaxis $(\mathrm{OR}=0.30 ; 95 \% \mathrm{Cl}, 0.15-0.58)$.

CONCLUSION Quality of care as measured by patients meeting CVD risk factors treatment goals was similar regardless of the sex of the patient or physician. Selected differences were found in the style of CVD risk factor management by sex of physician and patient.

Ann Fam Med 2010;8:25-32. doi:10.1370/afm.1071.

\section{INTRODUCTION}

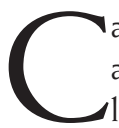

ardiovascular disease (CVD) remains the leading cause of morbidity and mortality in the United States for both men and women. ${ }^{1}$ The

large number of epidemiological studies and clinical trials that have documented the benefits of treating dyslipidemia, diabetes mellitus, hypertension, and obesity using behavioral and pharmacological means have led to clinical practice guidelines aimed at implementing these management recommendations. ${ }^{2-8}$ Several investigators have suggested that there may be sex disparities in the management of CVD and its risk factors and in the implementation of CVD risk factor clinical guidelines in primary care practice. ${ }^{9-21}$ Differences in the management of hypertension, dyslipidemia, obesity, and diabetes mellitus based upon the sex of the patient ${ }^{16-21}$ and of the physician and by patient-physician concordance by $\mathrm{sex}^{22-25}$ have been reported. Findings indicate that male and female physicians differ in their communication skills, practice styles, time spent with patients during encounters, and frequency of providing preventive services. ${ }^{22-34} \mathrm{Few}$ studies, if any, however, have examined the effects of the sex of the physician as a variable indepen- 
dent of other physician factors, such as years in practice, medical specialty, and the statistical effects associated with the clustering of patients by physicians in a practice in relation to CVD risk factor management. ${ }^{30-36}$ Because more than one-half of outpatient care in the United States occurs in the primary care setting, ${ }^{37}$ the purpose of this study was to conduct a multilevel analysis of the effects of the sex of the patient and physician, as well as physician-patient interactions by sex, on the management of CVD risk factors in primary care.

\section{METHODS}

\section{Study Design and Data Collection}

These analyses are based upon baseline data collected in 2004 as part of a cluster randomized trial aimed at testing the effectiveness of translating the Adult Treatment Panel III (ATP III) $)^{2}$ cholesterol treatment guidelines into primary care. The data collected were from 30 representative primary care physician practices in southeastern New England, comprising 55 primary care physicians and 4,195 patients. The data for these analyses came from medical record chart reviews, patient's telephone interviews, and physician's in-person questionnaires and interviews. The research and Health Insurance Probability and Accountability Act (HIPAA) ${ }^{38}$ protocol of physicians, staff, and patients were approved by the human subjects protection committee (Institutional Review Board) of Memorial Hospital of Rhode Island.

\section{Practice and Patient Recruitment}

To obtain a representative sample, letters were sent to all primary care physicians $(n=919)$ in southeastern New England. More than 100 physicians responded affirmatively, and 71 practices that were in close geographic proximity to the researchers were selected and stratified into large and small internal medicine and family medicine practices. From each of these strata, we randomly selected practices and obtained informed consent. We continued this process until we met our sample size requirement of 30 practices, for a total of 55 physicians.

After we obtained informed consent from the physicians and staff, all adult patients $(n=51,078)$ from the practices were sent a letter by their physician inviting them to participate in the project. After giving informed consent, 5,218 patients participated in a telephone interview during which each patient responded to a survey questionnaire that elicited information on age, sex, race/ethnicity, marital status, smoking status, physical activity, height, weight, daily serving of fruits and vegetables, education level, income level, and type of medical insurance coverage. Of these participants, 4,195 had their medical records abstracted, for a minimum of
20 charts and a maximum of 120 charts per physician. The physicians' information was obtained by completing a questionnaire and by public data from the state medical licensing board. Practice data were obtained from the physician's and office manager's questionnaire responses.

\section{Outcome Assessment (Chart Audits) and Data Collection}

We collected the patients' medical history, history of CVD, data on lipid disorder, hypertension, weight, diabetes mellitus, and smoking management from the medical records. The chart audit process is described in detail in Supplemental Appendix 1, available at http://www.annfammed.org/cgi/content/full/8/1/ 25/DC1. CVD risk factor management was based upon the medical record from the previous 5 years (1999-2004) for lipid management, and the previous 2 years for blood pressure, diabetes mellitus, smoking cessation, and obesity management.

\section{Measurements and Categorization}

Patients were categorized into 4 categories of coronary heart disease risk using the ATP III guideline risk categorization definitions. ${ }^{2}$ (1) low, (2) moderate, (3) high-risk, and (4) extremely high risk or equivalent of coronary heart disease. These definitions are described in detail in Supplemental Appendix 2, available at http://www.annfammed.org/cgi/content/ full/8/1/25/DC1. Patients with a lipid disorder, diabetes mellitus, or hypertension were identified either by documentation of diagnosis in the medical record or prescription of lipid, blood pressure, or glucoselowering medications with appropriate indications. Low-density lipoprotein (LDL) cholesterol goals were defined using the conservative LDL levels consistent with both the ATP III 2001 and 2004 updated guidelines, because chart audits were based upon data from 1999-2004, at which point the 2001 ATP III standards of care were operative. The LDL goals used were $<100$ $\mathrm{mg} / \mathrm{dL}$ for extremely high-risk patients or patients who had the equivalent of coronary heart disease, $<130 \mathrm{mg} /$ $\mathrm{dL}$ for moderate- and high-risk patients, and $<160 \mathrm{mg} /$ $\mathrm{dL}$ for low-risk patients. Among diabetic patients, an LDL goal was defined as $<100 \mathrm{mg} / \mathrm{dL}$, controlled blood pressure as $<130 / 85 \mathrm{~mm} \mathrm{Hg}$, and controlled diabetes as glycated hemoglobin $\mathrm{A}_{1 \mathrm{C}}\left(\mathrm{HgbA}_{1 \mathrm{C}}\right)$ levels $<7 \% .^{7}$ For patients with hypertension, controlled blood pressure was defined as blood pressure $<140 / 90 \mathrm{~mm} \mathrm{Hg}$ according to Joint National Committee recommendations (JNC 7). ${ }^{3}$ Physical activity advice was defined as documentation of physical activity recommendations in the chart. Dietary recommendations were defined as either physician dietary recommendations or documentation of nutrition referrals. CVD risk factor management 
was defined as management of a lipid disorder, weight control, hypertension control, diabetes control, and smoking cessation. Detailed definitions of CVD risk factor management are described in Supplemental

Appendix 3, available at http://www.annfammed.

ing org/cgi/content/full/8/1/25/DC1.

The primary variables of interest for this study were the sex of the patient and physician and their interaction. Patient sex was obtained from the telephone survey and physician sex was obtained from the physician's questionnaire. Patient variables included age, body mass index, marital status, education, medical insurance, CVD risk category, and medication use. Physician variables included sex, specialty, medical school graduation, number of patients seen per day, hours per week in patient care, and years in the practice. The cutpoints were chosen based upon the medians for the number of patients seen per day, hours spent in patient care per week, and years in practice. These physician variables met the criteria for confounding in our modeling selection process. Practice variables included practice size and practices with or without physician assistants or nurse practitioners that met the same modeling criteria or were believed necessary based upon the sampling strategy used.

\section{Statistical Methods}

Differences according to the sex of the patient and physician were examined using $t$ tests for continuous variables, and $\chi^{2}$ for categorical variables. A multilevel regression analysis was performed using generalized, linear mixed models to identify patient and physician differences by sex in CVD risk factor management after controlling for patient, physician, and practice confounding variables using SAS 9.1.3 GLIMMIX procedure (SAS Institute, Cary, North Carolina). The physician- and practice-level covariates were determined based upon being different by sex of the patient or physician and being statistically significant in multilevel modeling at $P<.10$. Practice-level covariates could have no missing data, could not be associated with physicianlevel variables, and were statistically significant at $P<.10$ in multilevel modeling or were part of the practice recruitment sampling strategy. We used $P<.10$ instead of $P<.05$ or $P<.20$ for model building to control for confounding bias and to include important covariates that might be excluded if we used the conservative $P<.05$, and to avoid overadjustment if we used $P$ $<.20 .{ }^{39}$ We report as statistically significant odds ratios and $95 \%$ confidence intervals at $P<.05$.

\section{RESULTS}

The number of patients with data analyzed was 4,195, of whom $40 \%$ were men and $60 \%$ were women. A comparison of patient characteristics and CVD risk factor by sex is displayed in Table 1 . Female patients were less likely to be partnered, to have a higher education, and
Table 1. Characteristics of Male and Female Patients

\begin{tabular}{|c|c|c|c|c|}
\hline Characteristic & $\begin{array}{l}\text { All } \\
\text { Participants }\end{array}$ & Male & Female & $\begin{array}{c}P \\
\text { Value }^{a}\end{array}$ \\
\hline Number participating, No. (\%) & $4,195(100)$ & $1,671(40)$ & $2,524(60)$ & \\
\hline Age, mean (SD), y & $52.53(13.3)$ & $53.14(12.9)$ & $52.1(13.5)$ & .13 \\
\hline Body mass index, mean (SD) & $28.34(6.03)$ & $29.09(4.88)$ & $27.96(6.59)$ & $<.001$ \\
\hline Race, white, \% & 95.1 & 94.67 & 95.40 & .77 \\
\hline Marital status, partnered, \% & 71.78 & 79.29 & 66.80 & $<.001$ \\
\hline \multicolumn{5}{|l|}{ Education level, \% } \\
\hline High school or less & 29.05 & 29.86 & 28.52 & \\
\hline Some college & 16.24 & 13.67 & 17.94 & $<.001$ \\
\hline College degree or higher & 54.71 & 56.47 & 53.54 & \\
\hline \multicolumn{5}{|l|}{ Income, \% } \\
\hline Less than $\$ 35,000$ & 15.38 & 10.60 & 18.87 & \\
\hline$\$ 35,000-\$ 74,999$ & 38.38 & 36.42 & 39.81 & $<.001$ \\
\hline$\$ 75,000$ or greater & 46.24 & 52.98 & 41.32 & \\
\hline \multicolumn{5}{|l|}{ Insurance, \% } \\
\hline Ensured overall & 98.59 & 98.86 & 98.42 & \\
\hline Private insurance & 80.43 & 81.51 & 79.71 & .02 \\
\hline Cardiovascular disease \% & 8.61 & 13.4 & 5.4 & $<.001$ \\
\hline Stroke, \% & 1.48 & 2.21 & 0.99 & .002 \\
\hline Congestive heart failure, \% & 1.62 & 1.92 & 1.43 & .28 \\
\hline Lipid disorder, \% & 52.3 & 62.8 & 45.3 & $<.001$ \\
\hline Hypertension, \% & 40.3 & 45.4 & 36.9 & $<.001$ \\
\hline Diabetes mellitus, \% & 9.7 & 11.7 & 8.3 & $<.001$ \\
\hline Current smokers, \% & 14.3 & 13.9 & 14.5 & .27 \\
\hline Physically inactive, \% & 23.2 & 22.5 & 23.7 & .22 \\
\hline Body mass index class, $\%$ & & & & $<.001$ \\
\hline$<25$ & 30.9 & 18.7 & 38.9 & \\
\hline $25-29.9$ & 36.4 & 45.9 & 30.1 & \\
\hline$>30$ & 32.7 & 35.3 & 31.0 & \\
\hline Cardiovascular disease risk, \% & & & & $<.001$ \\
\hline $\begin{array}{l}\text { Coronary heart disease } \\
\text { equivalent }\end{array}$ & 19.1 & 26.1 & 14.5 & \\
\hline High & 9.5 & 20.2 & 2.5 & \\
\hline Moderate & 20.3 & 18.7 & 21.3 & \\
\hline Low & 51.1 & 35.0 & 61.7 & \\
\hline
\end{tabular}


to have private insurance. In addition, coronary heart disease and stroke were less prevalent among female patients, and they were less likely to have a lipid disorder, hypertension, or diabetes.

A comparison of differences in physician characteristics by sex is displayed in Table 2 . Of the 39 male physicians and 16 female physicians that participated in this study, female physicians had a significantly higher percentage of female patients in their practices, whereas male physicians saw more patients per day and older patients. There was a trend toward a difference in patient care hours per week $(P=.10)$ and time behind by the end of the day $(P=.10)$, with female physicians being more behind and spending less time per week in patient care.

Cardiovascular risk factor management by sex of the patient and physician unadjusted for patient-, physician-, or practicelevel confounders is displayed in Table 3. Because some or most of the sex differences shown in Table 3 might be related to confounding by either patient-, physician-, or practice-level characteristics, we performed a multilevel regression analysis.

Table 4, stratified by patient and physician sex, displays the odds ratios and confidence intervals of these adjusted results. Many of the associations found in Table 3 were lost once adjusted for confounding. By comparing male patients with female patients, we did find that for diabetes care, more male patients were on medications for glucose control, were on angiotensin-converting enzyme (ACE) inhibitor therapy, and were on aspirin prophylaxis. For many CVD risk factors, women physicians were more likely than male physicians to counsel patients regarding diet, weight loss, and physical activity.

In our multilevel analysis, we found 3 significant patient-physician interactions by sex groupings (Figures 1 through 3$)$. Figure 1 shows that female physicians $(P=.03)$ were more likely to provide diet advice to their female patients with a lipid disorder. Figure 2 shows that female physicians $(P=.03)$ were less likely to prescribe ACE inhibitors to their diabetic female patients. Figure 3 shows that female physicians $(P<.05)$ were less likely to have blood pressure under control in their diabetic female patients.

\section{DISCUSSION}

The results of this study are intriguing and show that the quality of care as measured by patients meeting CVD risk factors treatment goals are similar regardless of the sex of the patient or physician. Many CVD risk factor management differences based upon the patient sex as enumerated in Table 3 are lost in multilevel adjustment. There do appear to be some differences in the use of medications regarding diabetes management, with male patients being more likely than female patients to have received glucose-lowering medications, ACE inhibitor therapy, and aspirin therapy. This finding may be due to sex-based differences in the stage and severity of the diabetes or sex-based differences in prescribing behavior. Our findings support previous studies showing that compared with female patients, more male patients get aspirin prophylaxis and ACE inhibitor therapy, ${ }^{40-46}$ whereas other studies do not confirm this disparity. ${ }^{35,36}$ The underuse of ACE inhibitors among female patients by female physicians might be explained by ACE inhibitor-associated cough, which has been reported to occur 2 to 3 times more frequently in women than in men. ${ }^{47}$ 
We can speculate that the sex concordance of female physicians with their female patients might make them more aware of this adverse effect and therefore prescribe it to fewer women. ${ }^{44}$

Compared with male physicians, female physicians appear to provide more counseling for a variety of CVD risk factors, including hypertension, obesity, and diabetes. Several other studies have examined malefemale differences in preventive services counseling for patients visiting primary care clinics and have found conflicting results. ${ }^{32}$ A recent analysis showed that among all visitors to primary care practices, patients of female physicians are more likely to receive health behavior counseling with no physician-patient sex concordance. ${ }^{34}$ Our study showed this same trend among patients with regard to CVD risk factor management. Thus, both male and female patients appear to be more likely to receive counseling services if they have a female physician, or it may be that female physicians are more likely to document these recommendations.

This study has several limitations that should be considered when interpreting our results. We are reporting CVD management behaviors documented in the medical record, and behaviors not documented were considered not done. Previous studies have shown that some behaviors may be performed but are not documented. It is unlikely that the documentation will be different by patient sex; however, documentation might be different by physician sex, because in our study, women physicians were more behind at the end of day and saw fewer patients. We did adjust for these confounding differences in our multilevel regression analysis. In addition, Flocke and Gilchrist, ${ }^{34}$ using direct observation rather than chart audits, found that female physicians provided more counseling than male physicians, a finding suggesting documentation is less likely to be an issue.

The data represent patients and physicians from southeast New England. The patients who agreed to participate in the study might not be representative of the entire patient population but may represent individuals with interest in CVD risk factor reduction. In

Table 3. Cardiovascular Risk Factors Management by Sex of Patient and Physician

\begin{tabular}{|c|c|c|c|c|c|c|}
\hline Management Characteristic & $\begin{array}{c}\text { Male } \\
\text { Patient } \\
\% \text { (No.) }\end{array}$ & $\begin{array}{l}\text { Female } \\
\text { Patient } \\
\% \text { (No.) }\end{array}$ & $\begin{array}{c}P \\
\text { Value }^{a}\end{array}$ & $\begin{array}{c}\text { Male } \\
\text { Physician } \\
\% \text { (No.) }\end{array}$ & $\begin{array}{c}\text { Female } \\
\text { Physician } \\
\% \text { (No.) }\end{array}$ & $\begin{array}{c}P \\
\text { Value }^{b}\end{array}$ \\
\hline \multicolumn{7}{|l|}{ Lipid management } \\
\hline LDL at goal & $59.14(621)$ & $58.48(668)$ & .865 & $58.36(949)$ & $59.50(340)$ & .693 \\
\hline Received advice for diet and weight loss & $72.10(757)$ & $72.59(829)$ & .982 & $67.62(1,135)$ & $78.61(451)$ & $<.001$ \\
\hline Received physical activity advice & $49.52(520)$ & $53.94(616)$ & .977 & $45.94(752)$ & $62.94(384)$ & $<.001$ \\
\hline Suggested medication for treatment & $66.10(694)$ & $60.33(689)$ & .039 & $64.10(1,056)$ & $58.03(327)$ & .049 \\
\hline On lipid-lowering medication & $57.81(607)$ & $53.59(612)$ & .179 & $57.14(937)$ & $50.27(282)$ & .020 \\
\hline \multicolumn{7}{|l|}{ Blood pressure management } \\
\hline Under control (<140/90 mg Hg) & $82.45(625)$ & $79.27(738)$ & .028 & $80.38(1,021)$ & $85.36(342)$ & .088 \\
\hline Under optimal control $(<120 / 80)$ & $17.68(134)$ & $19.98(186)$ & .408 & $18.41(229)$ & $23.28(91)$ & .063 \\
\hline Received advice for diet and weight loss & $72.16(547)$ & $68.74(640)$ & .116 & $65.53(864)$ & $77.13(323)$ & $<.001$ \\
\hline Received physical activity advice & $50.26(381)$ & $52.09(485)$ & .877 & $43.12(575)$ & $68.29(291)$ & $<.001$ \\
\hline On medication to control hypertension & $77.57(588)$ & $80.02(745)$ & .270 & $76.42(985)$ & $83.18(348)$ & .013 \\
\hline \multicolumn{7}{|l|}{ Weight management } \\
\hline Documented weight problems & $32.30(335)$ & $42.46(504)$ & $<.001$ & $39.27(648)$ & $33.28(191)$ & .113 \\
\hline Received advice for diet and weight loss & $72.23(749)$ & $71.27(846)$ & .432 & $69.52(1,147)$ & $78.05(448)$ & $<.001$ \\
\hline Received physical activity advice & $52.46(544)$ & $55.94(664)$ & .705 & $49.39(815)$ & $68.47(393)$ & $<.001$ \\
\hline \multicolumn{7}{|l|}{ Diabetes management } \\
\hline Under control $\left(\mathrm{HgA}_{1 c}<7 \%\right)$ & $68.37(134)$ & $66.99(140)$ & .756 & $65.44(195)$ & $73.83(79)$ & .113 \\
\hline On medication & $69.39(136)$ & $58.37(122)$ & .020 & $66.33(200)$ & $54.79(58)$ & .063 \\
\hline On aspirin therapy & $55.61(109)$ & $35.41(74)$ & $<.001$ & $47.81(143)$ & $36.59(40)$ & .078 \\
\hline On ACE medication & $51.53(101)$ & $41.06(85)$ & .038 & $48.82(145)$ & $38.68(41)$ & .084 \\
\hline On ARB medication & $24.49(48)$ & $20.77(43)$ & .347 & $25.25(75)$ & $15.09(16)$ & .040 \\
\hline BP under control (<130/85 mm Hg) & $62.76(123)$ & $56.94(119)$ & .227 & $59.04(176)$ & $61.45(66)$ & .681 \\
\hline LDL at goal & $48.47(95)$ & $42.58(89)$ & .196 & $48.16(140)$ & $38.58(44)$ & .142 \\
\hline Received advice for diet and weight loss & $80.10(157)$ & $86.60(181)$ & .033 & $79.24(242)$ & $83.17(96)$ & .329 \\
\hline Received physical activity advice & $52.04(102)$ & $63.64(133)$ & .019 & $48.55(152)$ & $74.25(83)$ & $<.001$ \\
\hline
\end{tabular}


a subsample of practices $(n=4)$, we compared random de-identified chart audits $(\mathrm{n}=350)$ with our identified chart audits $(\mathrm{n}=236)$. The 2 samples were similar in age, marital status, race, prescription benefits, frequency of

Table 4. Patient and Physician Sex Differences in Cardiovascular Risk Factor Management Using Multiple Level Regression Models

\begin{tabular}{lcc}
\hline Management & $\begin{array}{c}\text { Female vs Male } \\
\text { Patient } \\
\text { OR (95\% CI) }\end{array}$ & $\begin{array}{c}\text { Female vs Male } \\
\text { Physician } \\
\text { OR (95\% CI) }\end{array}$ \\
\hline $\begin{array}{l}\text { Lipid management } \\
\text { Suggest medication }\end{array}$ & $0.75(0.56-1.02)$ & $1.03(0.69-1.52)$ \\
Hypertension management & $0.61(0.36-1.03)$ & $1.61(0.90-2.89)$ \\
Blood pressure <140/90 mm Hg & $1.05(0.65-1.71)$ & $2.22(1.12-4.40)$ \\
$\begin{array}{l}\text { Advice for diet and weight loss } \\
\text { On blood pressure medication }\end{array}$ & $0.84(0.55-1.27)$ & $1.98(1.19-3.29)$ \\
Weight management & $0.93(0.66-1.31)$ & $2.14(1.30-3.51)$ \\
Advice for diet and weight loss & $1.00(0.74-1.34)$ & $2.03(1.3-3.18)$ \\
Physical activity advice & & \\
Diabetes management & $2.58(0.90-7.39)$ & $2.25(0.50-10.22)$ \\
Advice for diet and weight loss & $1.16(0.55-2.48)$ & $6.55(2.01-21.33)$ \\
Physical activity advice & $0.49(0.25-0.94)$ & $0.76(0.35-1.67)$ \\
Diabetes medication & $0.30(0.15-0.58)$ & $0.69(0.30-1.57)$ \\
Aspirin therapy & $0.39(0.22-0.72)$ & $0.82(0.41-1.64)$ \\
ACE inhibitor therapy & &
\end{tabular}

$\mathrm{ACE}=$ angiotensin-converting enzyme; $\mathrm{Cl}=$ confidence interval; $\mathrm{OR}=$ odds ratio.

Note: Adjusted for patients' variables: age (<55 vs $55+$ years), body mass index, education, marital status, type of medical insurance, on medication for the condition (lipid disorder, hypertension, diabetes mellitus), cerebrovascular disease risk.

Physicians' variables: sex, specialty (family medicine vs internal medicine), medical school graduation (US vs other), number of patients per day, (1-20/d vs $>20 / d$ ), number of hours per week in patient care (more or less than $40 \mathrm{~h} / \mathrm{wk}$ ), number of years in the practice (more or fewer than 16 years).

Practice variables: practice size (small vs large), practices with or without physicians' assistants.

Intracluster coefficients: lipid management, lipid-lowering medication, 0.10; hypertension management, blood pressure control, 0.08; dietary advice, 0.24 ; blood pressure medication, 0.04 ; weight loss-diet advice, 0.18; physical activity advice, 0.28; diabetes mellitus management, dietary advice, 0.21, glucose-lowering medication, 0.04 , physical activity advice, 0.36 , aspirin therapy, 0.10 .

\section{Figure 1. Lipid management: percentage of patients given diet} and weight loss advice.

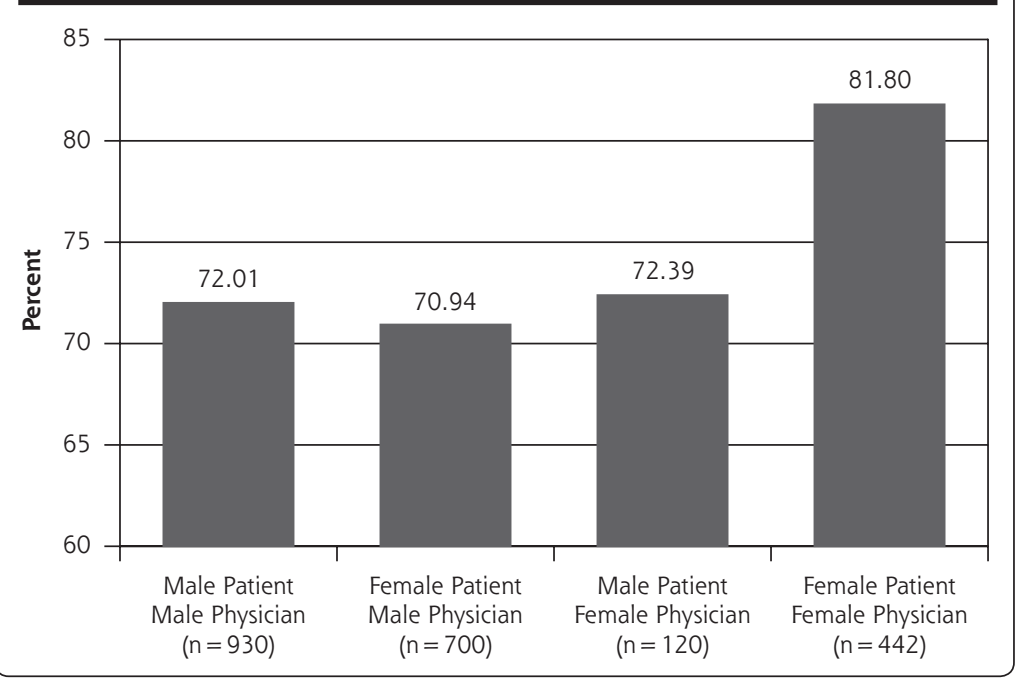

moderate-risk patients using the identified chart audits. Thus despite the $10 \%$ response rate, our results likely represent the patient characteristics and physician practice patterns of primary care physicians in southeastern New England. Generalizing the results to other patient populations and other physicians must therefore be done with caution. Regarding differences in CVD risk factor management by physician or patient sex, however, it is unlikely the differences in sampling strategy would affect our sex-specific results, because we were focusing on physician behavior as it relates to patient sex.

In summary, the differences in CVD risk factor management by patient and physician sex, after adjusting for patient, physicians, and practice differences, are modest, with the stylistic differences by physician sex in counseling frequency vs medication use having little effect on the frequency of patients meeting CVD guideline-specific goals during a 2- to 5-year period. Future research should explore whether the stylistic differences in CVD risk factor management found in our study have any long-term impact on clinically relevant outcomes, such as myocardial infarctions, strokes, heart failure, and death in longitudinal studies of primary care practice.

To read or post commentaries in response to this article, see it online at http://www. annfammed.org/cgi/content/full/8/1/25.

Submitted December 16, 2008; submitted, revised, May 21, 2009; accepted June 1, 2009.

A version of this report was presented at the North American Primary Care Research Group, October 20-23, 2008, Vancouver, British Columbia.

Key words: Gender; health disparities; cardiovas cular disease; risk factors

Funding support: This study was partially funded by Translating ATP III Cholesterol Guidelines into Primary Care Practice (grant No. 1 RO1 
Figure 2. Diabetes management: percentage of patients on angiotensin-converting enzyme therapy.

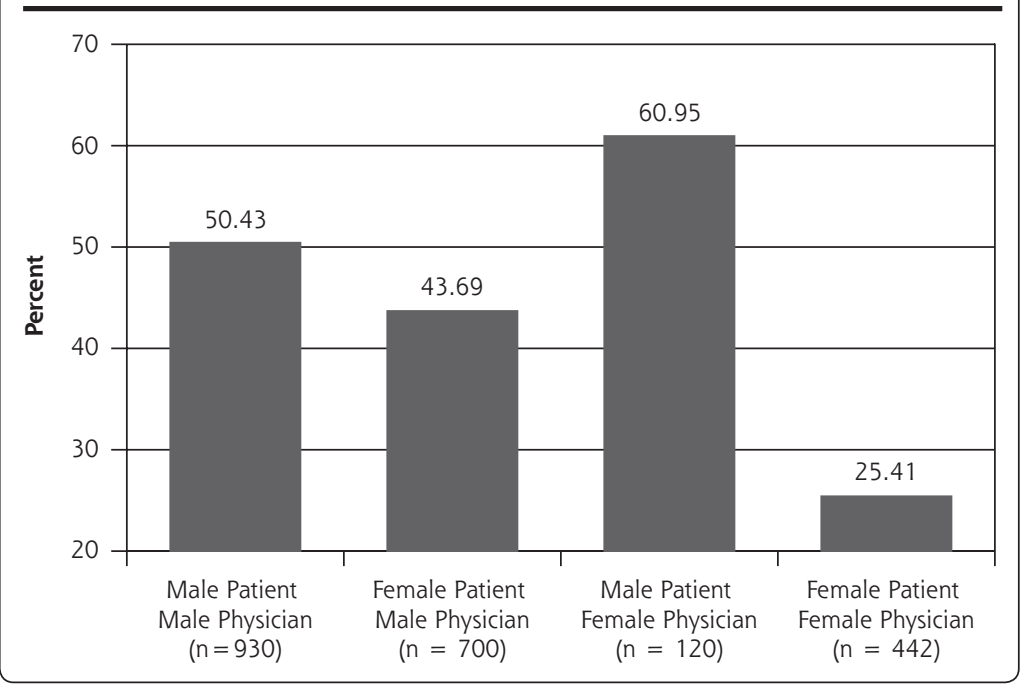

Figure 3. Diabetes management: percentage of patients with blood pressure under control.

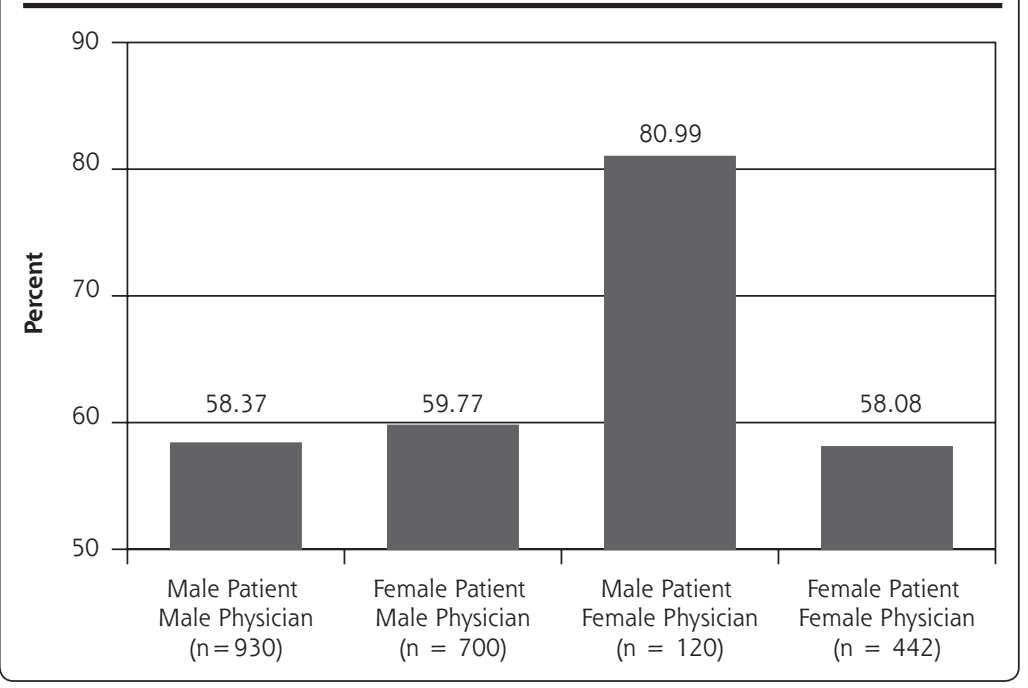

Parameswaran, MD, and Harold Sanders, MD, Newport, Rl; Elisabeth Farnum, MD, Cumberland Rl; Altaf Girach, MD, and Avanish Mehta, MD, Woonsocket, Rl; Robert J. Robbio, MD and John L. Bossian, DO, Wakefield, Rl; Bradford Kney, $M D$, Fall River, MA; Joseph A. DiLorenzo, MD, Cranston, Rl; Steven Flood, MD, Richard Popovic, $M D$, and Patricia Kearney, MD, Foxboro, MA; Hao Yuan Huang, MD, Cranston, Rl; Hugo Yamada, $M D$, and Hua Chung Lu, MD, Lincoln, Rl; Michael Baaklini, MD, and Raffi Calikyan, MD, Bristol, RI; Eaine B. Fain, MD, Pawticket, Rl; Martin Miner, MD, James Lippencott, MD, Mark Ringiewicz, MD, Priscilla Shube, MD, Hugh Woolverton, MD, and Jeffrey Syme, MD, Swansea, MA; Margaret Sun, MD and James Schwartz, MD, E Providence, Rl; Martin Kerzer, DO, Warwick, Rl; Jerome McMurray, MA; Mary Roberts, MS; Susan Howard; Barry Clarke; and Sherri Campbell.

\section{References}

1. American Heart Association and the American Stroke Association. Heart Disease and Stroke Statistics-2005 Update. Dallas, TX: American Heart Association; 2005. http://www.americanheart.org.

2. US Department of Health and Human Services; National Institutes of Health; National Heart Lung and Blood Institute. Third Report of the National Cholesterol Education Program (NCEP) Expert Panel on Detection, Evaluation and Treatment of High Blood Cholesterol in Adults (Adult Treatment Panel III) Final Report. NIH Publication No. 02-5215. Sep 2002:1-284.

3. Chobanian AV, Bakris GL, Black HR, et al.; National Heart, Lung, and Blood Institute Joint National Committee on Prevention, Detection, Evaluation, and Treatment of High Blood Pressure; National High Blood Pressure Education Program Coordinating Committee. The Seventh Report of the Joint National Committee on Prevention, Detection, Evaluation, and Treatment of High Blood Pressure: the JNC 7 report. JAMA. 2003;289(19):2560-2572.

4. Appel LJ, Champagne CM, Harsha DW, et al; Writing Group of the PREMIER Collaborative Research Group. Effects of comprehensive lifestyle modification on blood pressure control: main results of the PREMIER clinical trial.

HL70804) and Translating ATP III Cholesterol Guidelines Supplement Project-Qualitative Study (grant No. 1 RO1 HL70804).

Acknowledgments: We would like to thank the following physicians and their practice staff: Charles Cronin III, DO, and Richard DelSesto, MD, E Greenwich, Rhode Island; Daniel Hochberger, MD, Rumford, RI; Robert Cicchelli, MD, and David Cunningham, MD, Middletown, RI; Amrut Patel, MD, Cranston, Rl; Linda A. DeLuca, MD, Lincoln, Rl; Kim J. Crawford, MD, N Scituate, RI; Robert Lambe, MD, Margaret Koehm, MD, James Macek, MD, and Christine Robb, MD, Plainville, Massachusetts; David Leibowitz, DO, Warren, RI; Colleen A. Cleary, MD, Pawtucket, Rl; David Carter, MD, Mark Braun, MD, Peter Hollmann, MD, and Usha Panneerselvam, MD, Cranston, RI; David Kerzer, DO, and Matthew Salisbury, MD, Cranston, RI; Daniel T. Shreve, MD, E Providence, RI; Kelly A. McGarry, MD, Anne Moulton, MD, Iris Tong, MD, and Michelle Stozek, MD, Providence, RI; Leilani Nixon, MD, Putnam, Connecticut; Michael C. Souza, DO, E Providence, RI; David Gorelick, MD, Jayanthi
JAMA. 2003:289(16):2083-2093.

5. Knopp RH, d'Emden M, Smilde JG, Pocock SJ. Efficacy and safety of atorvastatin in the prevention of cardiovascular end points in subjects with type 2 diabetes: the Atorvastatin Study for Prevention of Coronary Heart Disease Endpoints in non-insulin-dependent diabetes mellitus (ASPEN). Diabetes Care. 2006;29(7):1478-1485.

6. Grundy SM, Cleeman JI, Merz LN. Heart, Lung and Blood Institute; American College of Cardiology Foundation; American Heart Association. Implications of recent clinical trials for the National Cholesterol Program Adults Treatment Panel III Guidelines. Circulation. 2004;110(2):227-239.

7. American Diabetes Association. Standards of medical care in diabetes-2006. Diabetes Care. 2006;29(Suppl 1):S4-S42.

8. Elmer PJ, Obarzanek E, Vollmer WM, et al.; PREMIER Collaborative Research Group. Effects of comprehensive lifestyle modification on diet, weight, physical fitness, and blood pressure control: 18-month results of a randomized trial. Ann Intern Med. 2006;144(7):485-495. 
9. Correa-de-Araujo R, Stevens B, Moy E, Nilasena D, Chesley F, McDermott K. Gender differences across racial and ethnic groups in the quality of care for acute myocardial infarction and heart failure associated with comorbidities. Womens Health Issues. 2006;16(2):44-55.

10. Harrold LR, Lessard D, Yarzebski J, Gurwitz JH, Gore JM, Goldberg RJ. Age and sex differences in the treatment of patients with initial acute myocardial infarction: a community-wide perspective. Cardiology. 2003;99(1):39-46

11. Kattainen A, Salomaa V, Jula A, et al. Gender differences in the treatment and secondary prevention of CHD at population level. Scand Cardiovasc J. 2005;39(6):327-333.

12. Gold LD, Krumholz HM. Gender differences in treatment of heart failure and acute myocardial infarction: a question of quality or epidemiology? Cardiol Rev. 2006;14(4):180-186.

13. Edwards ML, Albert NM, Wang C, Apperson-Hansen C. 19932003 gender differences in coronary artery revascularization: has anything changed? J Cardiovasc Nurs. 2005;20(6):461-467.

14. Jacobs AK. Women, ischemic heart disease, revascularization, and the gender gap: what we missing? J Am Coll Cardiol. 2006;47 (3 Suppl):63-65.

15. Abuful A, Gidron Y, Henkin Y. Physicians' attitudes toward preventive therapy for coronary artery disease: is there a gender bias? Clin Cardiol. 2005;28(8):389-393.

16. McBride SM, Flynn FW, Ren J. Cardiovascular alteration and treatment of hypertension: do men and women differ? Endocrine. 2005;28(2):199-207.

17. Kim C, Beckles GL. Cardiovascular disease risk reduction in the behavioral risk factor surveillance system. Am J Prev Med. 2004;27(1):1-7.

18. Goff DC Jr, Bertoni AG, Kramer H, et al. Dyslipidemia prevalence, treatment, and control in the Multi-Ethnic Study of Atherosclerosis (MESA): gender, ethnicity, and coronary artery calcium. Circulation. 2006;113(5):647-656.

19. Bittner V. Perspectives on dyslipidemia and coronary heart disease in women. J Am Coll Cardiol. 2005;46(9):1628-1635.

20. Trynosky KJ. Missed targets: gender differences in the identification and management of dyslipidemia. J Cardiovasc Nurs. 2006;21(5): 342-346.

21. Sarafidis PA, McFarlane SI, Bakris GL. Gender disparity in outcomes of care and management for diabetes and the metabolic syndrome. Curr Diab Rep. 2006;6(3):219-224.

22. Roter DL, Hall JA, Aoki Y. Physician gender effects in medical communication: a meta-analytic review. JAMA. 2002;288(6):756-764.

23. Kaplan SH, Greenfield S, Ware JE Jr. Assessing the effects of physician-patient interactions on the outcomes of chronic disease. Med Care. 1989;27(3)(Suppl):S110-S127.

24. Kim C, Hofer TP, Kerr EA. Review of evidence and explanations for suboptimal screening and treatment of dyslipidemia in women. A conceptual model. J Gen Intern Med. 2003;18(10):854-863.

25. Street RL Jr, O'Malley KJ, Cooper LA, Haidet P. Understanding concordance in patient-physician relationships: personal and ethnic dimensions of shared identity. Ann Fam Med. 2008;6(3):198-205.

26. Boulis AK, Long JA. Gender differences in the practice of adult primary care physicians. J Womens Health. 2004;13(6):703-712.

27. Bertakis KD, Azari R. Patient gender and physician practice style. J Womens Health. 2007;16(6):859-868.
28. Tabenkin H, Goodwin MA, Zyzanski SJ, Stange KC, Medalie JH. Gender differences in time spent during direct observation of doctorpatient encounters. J Womens Health (Larchmt). 2004;13(3):341-349.

29. Franks P, Bertakis KD. Physician gender, patient gender and primary care. J Womens Health (Larchmt) 2003;12(1):73-80.

30. Lurie N, Slater J, McGovern P, Ekstrum J, Quam L, Margolis K. Preventive care for women. Does the sex of the physician matter? N Engl J Med. 1993;329(7):478-482.

31. Kreuter MW, Strecher VJ, Harris R, Kobrin SC, Skinner CS. Are patients of women physicians screened more aggressively? A prospective study of physician gender and screening. J Gen Intern Med. 1995;10(3):119-125.

32. Schmittdiel J, Grumbach K, Selby JV, Quesenberry CP Jr. Effect of physician and patient gender concordance on patient satisfaction and preventive care practices. J Gen Intern Med. 2000;15(11): 761-769.

33. Henderson JT, Weisman CS. Physician gender effects on preventive screening and counseling: an analysis of male and female patients' health care experiences. Med Care. 2001;39(12):1281-1292.

34. Flocke SA, Gilchrist V. Physician and patient gender concordance and the delivery of comprehensive clinical preventive services. Med Care. 2005:43(5):486-492.

35. Kim C, McEwen LN, Gerzoff RB, et al. Is physician gender associated with the quality of diabetes care? Diabetes Care. 2005;28(7): 1594-1598.

36. Berthold HK, Gouni-Berthold I, Bestehorn KP, Böhm M, Krone W. Physician gender is associated with the quality of type 2 diabetes care. J Intern Med. 2008;264(4):340-350.

37. Schappert SM. National Ambulatory medical care survey: 1994 summary. Advance data from vital and health statistics. Adv Data. 1996;273(273):1-18.

38. United States Department of Health and Human Services. OCR Privacy Brief. Summary of the HIPAA Privacy Rule. http://www.hhs. gov/ocr/privacysummary.pdf. Accessed Nov 10, 2008.

39. Mickey RM, Greenland S. The impact of confounder selection criteria on effect estimation. Am J Epidemiol. 1989;129(1):125-137.

40. Nguyen KX, Marinac JS, Sun C. Aspirin for primary prevention in patients with diabetes mellitus. Fam Med. 2005;37(2):112-117.

41. Cull CA, Neil HAW, Holman RR. Changing aspirin use in patients with Type 2 diabetes in the UKPDS. Diabet Med. 2004;21(12):1368-1371.

42. Petri A, de Lusignan S, Williams J, Chan T, Majeed A. Management of cardiovascular risk factors in people with diabetes in primary care: cross-sectional study. Public Health. 2006;120(7):654-663.

43. Wexler DJ, Grant RW, Meigs JB, Nathan DM, Cagliero E. Sex disparities in treatment of cardiac risk factors in patients with type 2 diabetes. Diabetes Care. 2005;28(3):514-520.

44. Roter DL, Hall JA. How physician gender shapes the communication and evaluation of medical care. Mayo Clin Proc. 2001;76(7):673-676.

45. Allende-Vigo MZ. Cardiovascular disease in women with diabetes mellitus: a review. P R Health Sci J. 2004;23(3):193-197.

46. Egede LE, Zheng D. Modifiable cardiovascular risk factors in adults with diabetes: prevalence and missed opportunities for physician counseling. Arch Intern Med. 2002;162(4):427-433.

47. Hayes N Sh, Taler SJ. Hypertension in women: Current understanding of gender differences. Mayo Clin Proc. 1998;73(2):157-165. 